survey of the subject from the $x$-ray point of view. It is a pleasure to welcome Prof. Ross Golden's monograph and to pronounce it a work, from an authoritative pen, of first importance to radiologists and gastroenterologists.

The author's survey of the subject is very complete. He begins with a general introduction describing the indications for a small intestine study, and the technique both of the small intestine meal and the small intestine enema. Then follows an account of the embryology, anatomy, and physiology of the jejunum and ileum; and in discussing the physiology an account is given of the chemical mediator theory of nerve transmission and its application to the movements of the small gut. The author then describes the $x$-ray appearances in the normal small intestine, including the appearances in the infant-a subject that has received too little attention in the past.

In the section on obstructive and paralytic ileus there is a complete and informative account of the use of the Miller Abbott tube in diagnosis and treatment, which will be of great value to all who attempt this technique. One of the most important chapters is that on the $x$-ray picture of the intestine in disorders of nutrition: the physiological mechanism is discussed, and the nonspecificity of the changes wisely emphasized. Diseases of the mesentery, allergy, inflammation, neoplasms, congenital abnormalities, the effects of drugs, and miscellaneous conditions are described in later chapters, and the book ends with a bibliography of 200 references.

The print is readable, the book is free from padding, and the illustrations arewwell chosen and reproduced. It is a monograph to be recommended to all who are interested in this comparatively unexplored region. They will find in it much of interest and help in their work.

\section{CLINICAL ELECTROCARDIOGRAPHY}

Electrocardiography in Practice. By Ashton Graybiel, M.D., and Paul D. White, M.D. With the assistance of Louise Wheeler, A.M., and Conge Williams, M.D. Second edition, revised. (Pp. 458; 323 illustrations. 35s.) London: W. B. Saunders Company. 1946.

For the clinical exploration of the heart muscle the conventional limb lead electrocardiogram is no longer.always sufficient. This fact is well demonstrated by Graybiel and White in the second revised edition of Electrocardiography in Practice. They show that, in general, an acute myocardial lesion may be inferred from the analysis of limb leads but that in some cases it will only be registered when the precordial leads are paired with one arm, the left foot, or the Wilson central terminal The authors have given a readily understandable and fully illustrated account of this matter. While in this country the chest lead paired with the right arm is the technique in routine use, Graybiel and White consider that the Wilson central terminal will prove more satisfactory as it shows less potential variation than any single extremity. Errors of electrocardiographic interpretation are as likely to arise from lack of familiarity with the range of the normal as from failure to recognize an actual abnormality. This very real problem is excellently dealt with in Part II of the work. Later sections are devoted to the arrhythmias and the types and patterns of electrocardiograms in relation to aetiology. All the well-known aetiological groups are surveyed, and, in addition, the acute infections, nutritional and endocrine disorders, and the cor pulmonale to which the authors have made important clinical as well as cardiographic contributions. The presentation of a number of electrocardiograms for practice in interpretation will help readers to assess their own knowledge of the subject. Whatever is the result of this test there is no doubt that study of Graybiel and White's work will make many obscure points plain and fill some lacunae in the knowledge of almost every reader.

\section{Notes on Books}

Reconstruction by Way of the Soil, by G. T. WRENCH, is published at $12 \mathrm{~s}$. 6d. by Faber and Faber. In elaborating the title of his book, $\mathrm{Dr}$. Wrench develops the thesis that farming is an art and something infinitely wider than scientific agriculture. It is a "Way of Life" itself. The family as a group is but a human complement of the soil itself, both family and soil recreating life. In the first three chapters he deals with the intensive personal agriculture which gave to the early Romans their physiological vigour and virile character. Aithough the carcass feeding of Polar Eskimos plays almost the same prominent part as in beasts of prey, the lactovegetarian diet, wholemeal grain, fruits, vegetables, milk and its products are referred to as the food of many of the healthiest and strongest peoples of the present day. War and history depend much upon man's attitude to the soil. The author shows that although this attitude is ignored by historians it will give rise to a greater knowledge of the causes of devastating war and its prevention. Nomads and speculators who lead an ill-baianced life by not following the "rule of return" which is the only stable rule of living regard the soil as something to be exploited-even plundered -for their own gain, as a means to mastery and wealth. A more true valuation of the soil and its effects wouid be a powerful factor in the maintenance of peace. After dealing with the economics of soil, the proper and wrongful use of urban and rural waste, and the wonderfully successful methods of primitive farmers, Dr. Wrench has an interesting chapter on the effects of the dominance of money. The subject of this book is world wide: it calls for a means of action in reconstruction via the soil.

The Association of Special Libraries and Information Bureaux ("Aslib") has issued a Catalogue of Films of General Scientific Interest in Great Britain compiled by the Scientific Film Association. The classified subject index has five columns of entries under the general heading "Medical and Para-Medical Sciences," with a number of sub-headings. The catalogue can be obtained for $5 \mathrm{~s}$. $3 \mathrm{~d}$. post free from Aslib, 52, Bloomsbury Street, London, W.C.1.

General Bacteriology Laboratory Manual, by L. S. McClung of the University of Indiana, consists of instructions for 61 sessions of practical work in general bacteriology, with spaces for recording results. Though teachers of medical bacteriology rarely have time for dealing with the fundamentals of the subject in so extensive a way as this, they may nevertheless gain some useful ideas for the practical teaching of bacterial morphology and physiology. The publishers are W. B. Saunders Company, and the price is 6s. $6 \mathrm{~d}$.

Correction.-We regret that the name of the publishers of Principles of Dynamic Psychiatry by Jules H. Masserman was incorrectly given in our issue of Oct. 19 (p. 579). Messrs. W. B. Saunders Company Ltd. are the publishers of this book.

\section{Preparations and Appliances}

\section{COMBINED HAEMOSTAT AND NEEDLE-HOLDER}

\section{Dr. J. S. Laurie (Pontefract) writes:}

Since the description (B.M.J., Sept. 9, 1944) of my use of a hollow curved perineum needle for obstetric work, it appears that very widespread interest has been aroused in this simple little instrument. Messrs. C. F. Thackray, of Leeds, who made the original needle for me. have kindly designed a combined

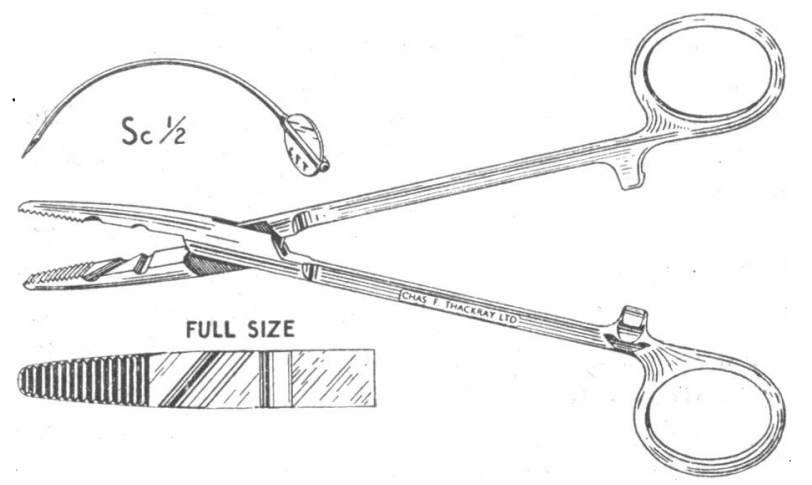

haemostat and needle-holder in stainless steel, with grooves in the jaws permitting the needle to be gripped at either of two angles without damaging its lumen.

I have found this instrument very useful in giving more purchase and thus minimizing still more the discomfort to the tired mother, while the variation of angle covers most of the awkward positions in which one may have to work in domestic midwifery. It is of interest to note also that stitches with the round needle have much less tendency to cut out than those with a cutting needle as normally used.

The haemostat end saves duplication of instruments in an already crowded bag. 